\title{
Augmented reality as a new way of exploring the city: unified platform for data providers
}

\author{
J. Trojan ${ }^{1}$, S. Chudáček ${ }^{2} \&$ P. Chrastina ${ }^{1}$ \\ ${ }^{1}$ Faculty of Logistics and Crisis Management, \\ Tomas Bata University in Zlín, Czech Republic \\ ${ }^{2}$ Czech Academy of Sciences, Institute of Geonics, Czech Republic
}

\begin{abstract}
The purpose of the paper is to present the ways of using augmented reality as part of location based services. These tools have become very popular after the mass using of smart phones and navigation technologies. The objective of the paper is to introduce a unified web-based platform invented for data providers for smarter transformation of the static data. We used developer's interfaces of the most popular augmented reality mobile apps (Layar and Wikitude) to utilize them in to the user-friendly web platform which provides comfort for content creators. Thus we have a simple and very effective tool for dynamization of static data (points of interests in the cities) to the dynamize form suitable for augmented reality apps. The implementation of the web-based platform is being realized among Czech destination management organizations and will be released under the open source license. This approach comes with the unique benefits for data providers/content creators and could bring new point of view for big data presentation to the public. Keywords: augmented reality, cyberspace, city navigation, regional development.
\end{abstract}

\section{Introduction}

Augmented reality (AR) belongs to the phenomenon of modern times [1], so it is obvious that the significance of presenting spatially-enabled data to users is very high. Using cyberspace to download data and view them in real (material) world [2] is very popular not only in the game industry (see, e.g. Pokemon GO mobile adventure) but also in other cases (examples in [3-5]). Augmented reality is part of location-based services (LBS). Users encouraged by the mass using of smart mobile phones (or other accessories like tablets, wearables etc.) seek more and 
more for services such as finding the nearest shop, entertainment and other facilities in the (space of) city. Today's concept of smart cities (see e.g. [6-8]) must use and utilize the big amount of data mainly come from citizens [9]. Citizen science belongs to the huge group of VGI - volunteered geographic information. Utilizing big data and presenting them to citizens must be done sophistically but easy to use by citizens. This concept is simply named as neogeography $[10,11]$ and follows the trend of ubiquitous computing [12].

Virtual activities mentioned above are part of the cyberspace, an emerging topic in current science [13-15]. In modern cities, most of the activities are connect to the tourism $[16,17]$, some studies even identified urban tourism as a major driving force of further AR development [18]. Understanding the AR concept in sustainable and regional development of the city is essential for making viable and useful location-based services. Technological overview covers dimension of programming for HTML 5, ASP.NET and other platforms [19-23] and design creation [24] together with special tools specified by certain mobile AR applications [25].

\section{State-of-the-art in the modern cities}

Local governments and public sector might to have their own applications of AR which could help citizens or tourists to discover the city using mobile phones. Some of the cities developed their own application - e.g. cities within the Tuscany region, Basel, Philadelphia - more examples in $[16,18]$. Still, for most of the cities, the easiest way is to create a content for existing AR application. The advantages are simple - you do not need to spend money for the application development, maintenance and platform utilization. Applications which are currently being offered by third parties to explore the city are Wikitude [26-28] and Layar [29-31]. Since 2015 there was also an application from the Metaio company called Junaio, which was bought by Apple and its development stopped. All of the presented applications are cross-platform (which means you could download them from iTunes or Google Play or Windows Store) and free of charge for basic users. For all applications it is also possible to developed own content and get it published. This way seems to be suitable for smaller cities or for those of them which do not have their own application. One of the advantage of using the well-known application is also the user awareness - it is more likely that users will have installed some of the global AR applications than just one for the local area, usable only in specified city [32]. The problem is that the content dynamization (transformation of static points of interests/POIs in to dynamic AR services) is not so easy. Thus, we are working on unified web-based platform which could make easier for data providers to publish their data into the cyberspace as AR content. Such platform should be accessible by URL address and could offer easy way of turn provider's data to specific format, which could be directly uploaded to Layar and Wikitude application. 


\section{Prerequisites, initial situation and recommended workflow}

The basic vision is to create a unified platform for data providers to dynamize their own POIs and then view them in the two most widely used AR browsers without the need of programming. First of all, it is assumed that the user is able to create a simple table file in the Office Open XML (XLSX) or Excel Binary (XLS) file format. The platform should be designed for the two most widespread AR applications - Wikitude and Layar. Each of these applications has its own specific requirements (see [26-31]) and their speed and stability depend on the hardware performance of the mobile smartphone, used wearable or tablet [32]. The recommended process of data transfer is performed in three steps as shown in fig. 1 .

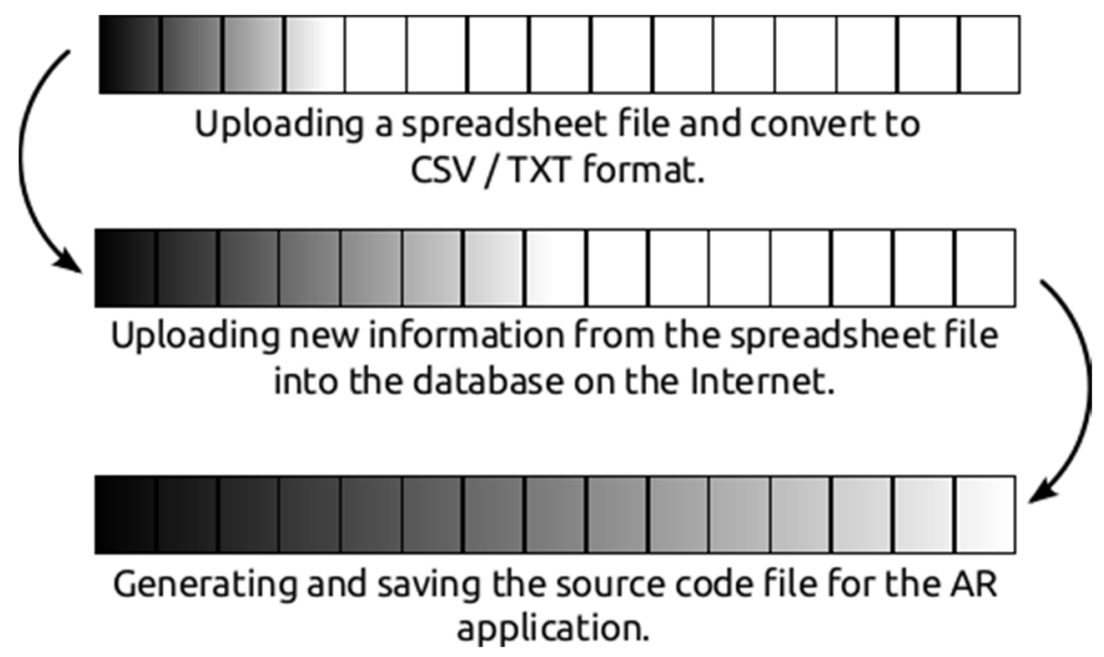

Figure 1: The workflow of POI transfers [32].

Using the office suite (e.g. Microsoft Office or LibreOffice as an open source alternative) installed on the computer, the first step is to create a spreadsheet file that contains information about the POIs determined to be dynamized into AR. The information suitable for the platform could be as follows:

- name of the POI (the title of a POI is the name for a particular point of interest),

- short and long descriptions,

- locations specified by GPS coordinates used to display a POI in the AR or on a map

- and other relevant information which could be used by specified AR application (such as e-mail, telephone, picture/photo etc.), as an example see fig. 2 . 
After creating the spreadsheet, the next step is to upload the layer (i.e. the POIs) stored in XLS/XLSX format to the web environment. The information from the spreadsheet is then processed by subscribing to an online MySQL database and links are generated by the source code which the user can simply copy to the respective AR browsers for smartphones (Layar or Wikitude) via the web interface [32].

The last step for the data provider is to set certain parameters (the generated links, text colour in the applications, logo of the layer etc.) in a user-friendly interface.

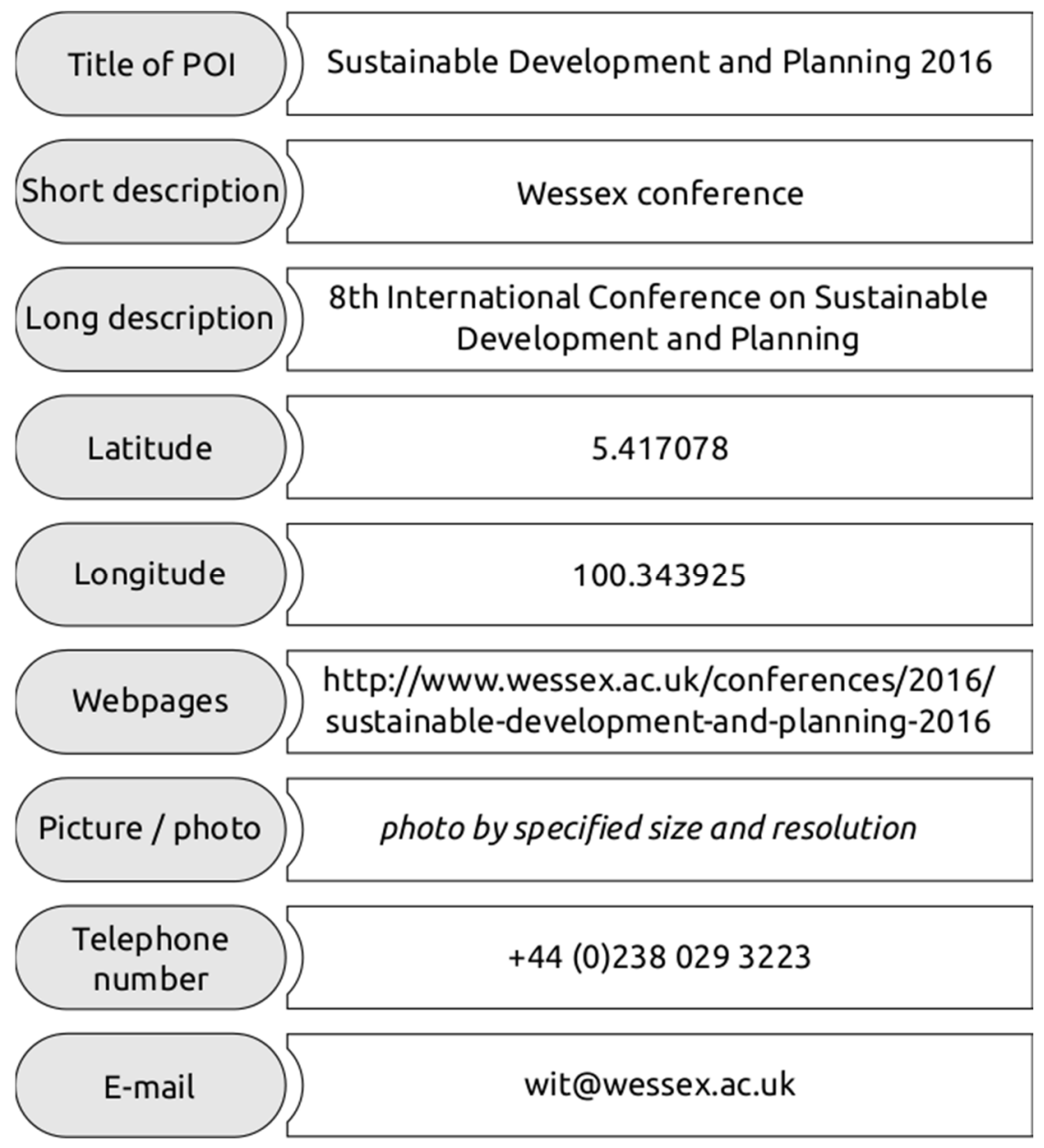

Figure 2: $\quad$ Pattern of input spreadsheet [32].

The technical criteria for the transfer of the spreadsheet file into the database are described by the author [32]. 


\section{Results: unified web platform and AR environment}

The transcription of the XLSX or XLS spreadsheet is done in the web environment in three basic steps (fig. 3). According to authors [32], most of the steps are executed automatically by the algorithm. The web platform also offers the option to change the access to user data, displaying all POIs that are currently found in the database (including the option to download previously uploaded spreadsheet files). There is also the option to reverse validation of the last five entries in the database which are compared to the five most recent entries in the spreadsheet file, and to find a particular POI stored in the database by specifying a query.

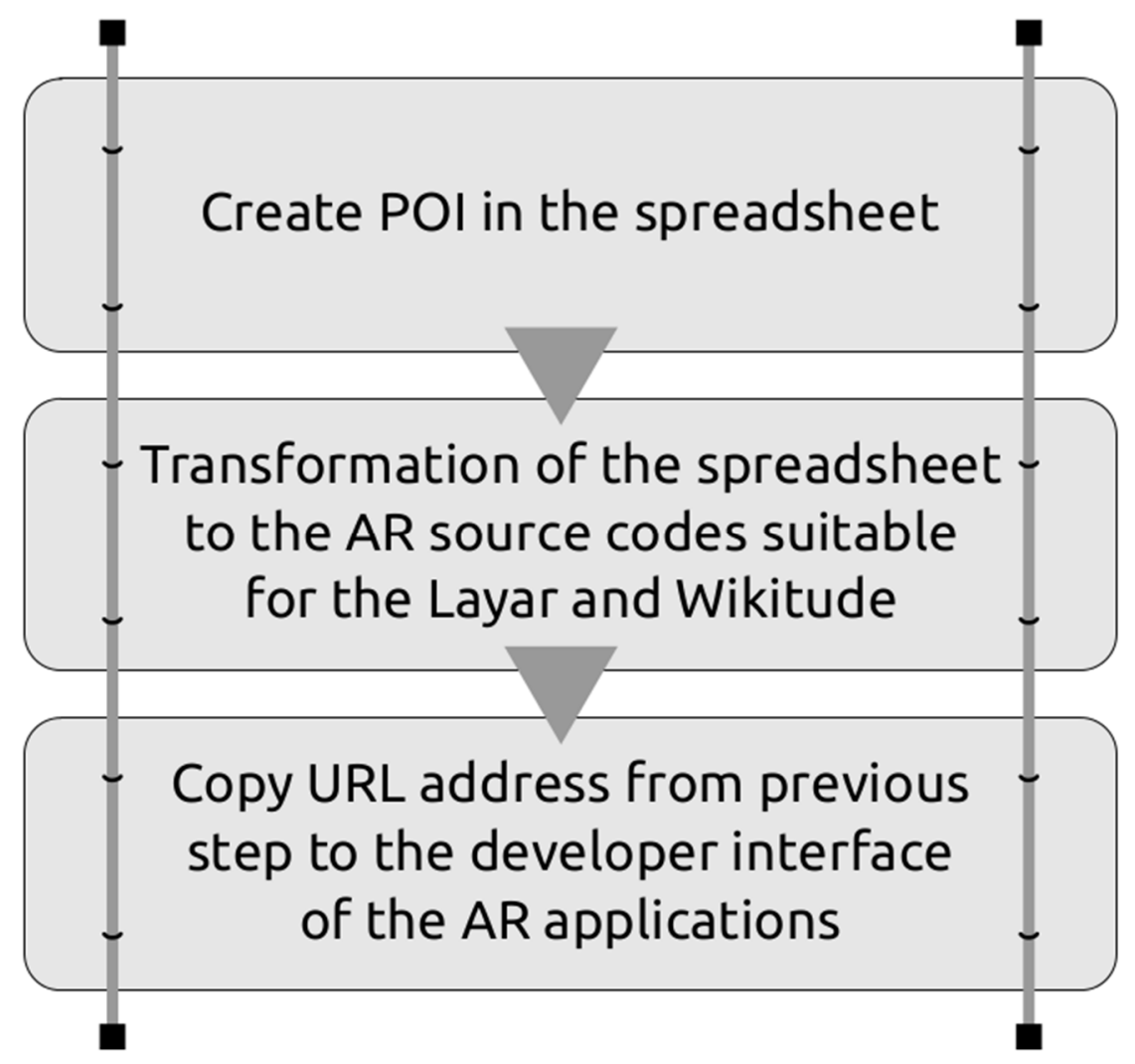

Figure 3: The process of data transcription on the website [32].

Links generated based on the description above are inserted into the user's web interface of an AR browser. In both applications, access to this interface and the layer creation is free. Each application has a slightly different environment of the interface; however, all the interfaces can be used intuitively and are easy for the control [32]. 
During the creation of new layers, the following criteria must be met:

- $\quad$ the developer (data provider) must enter the name and description of a new layer,

- $\quad$ the developer (data provider) must upload the new layer's logo,

- $\quad$ the developer (data provider) must enter information about the author and refer to the generated link, which provides information about the POI.

It is highly recommended that the next step for the data provider (layer creator, developer) is to test the layer on smartphone or tablet, and specify the characteristics of individual layers. The final step is to make the layers visible for the general public. From this moment on, every user can search (for) the layers and view the POIs on his or her mobile electronic device [32].

\section{Discussion of further research and model implementation}

Presented web based platform for data providers in the cities and destinations is proof-of-concept that worked fine for the Czech Tourism Authority CzechTourism. For this authority we have prepared dynamization of more than 2,000 POIs of ten different classified categories (under the project mapping the cultural and architectural heritage of the Czech Republic). The POIs were first prepared in a spreadsheet table to which coordinates and other attributes were later added (fig. 4 shows the other implementation of the best Czech restaurants). In this way a dynamized tourist guide was produced, verifying the methodology of POI dynamization in the process.

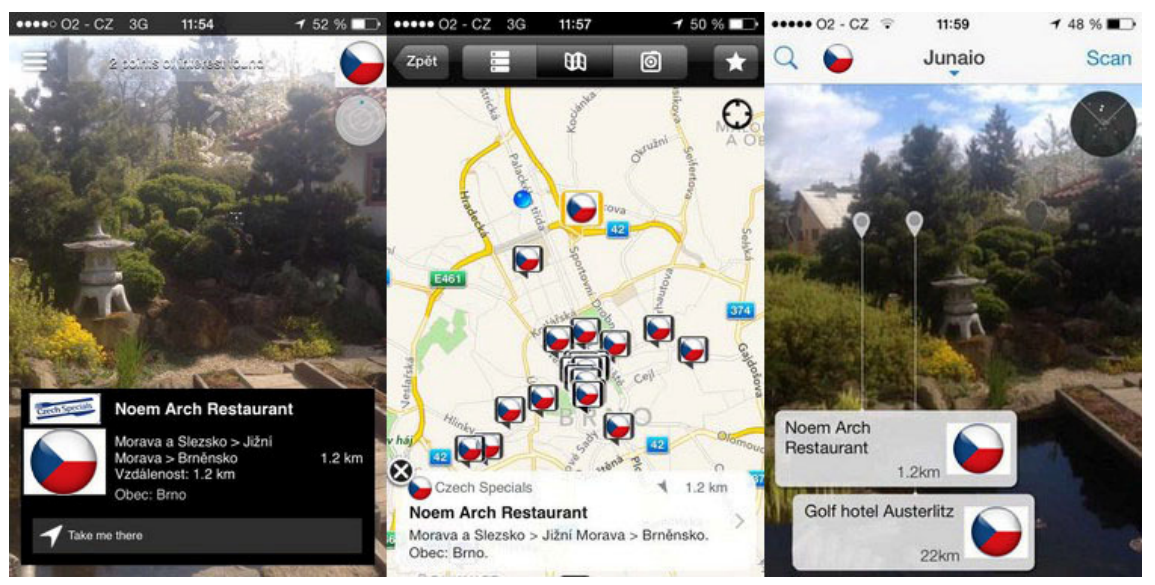

Figure 4: The proof-of-concept layer in augmented reality: the Layar, Wikitude and former Junaio AR browsers. Various types of views.

Further research is also conducted under the financial mechanisms of Czech national sources - especially the Technological Agency of the Czech Republic 
with the focus on usage in industrial heritage. This project tends to merge digital information of industrial objects with the real environment of industrial landscape. The core theme of citizen science is also part of the project COST financed by grant schemes of the European research grants (COST action 15212).

\section{Conclusion}

This paper presented a unified platform for POI dynamization which could bring new ways of exploring the city using AR concepts. The platform could dynamize the static lists of points of interest (POIs) stored in the spreadsheets to the most widely used augmented reality (AR) mobile device browsers Layar and Wikitude. This could simplify the approach to creating virtual content in the cyberspace for citizens and tourists. Real-time updating of POIs via the web interface should be made user-friendly as much as possible without the need to log in different developer zones.

However, as we did before [32], we should clearly emphasize disadvantages of the whole concept of delivering information to masses using AR principles. First of all, we should deal with content creators who assign wrong information to the content offered by AR applications. This is very difficult to solve due to open concept of all platforms. Some authors also dealt with privacy [24] or technical issues of data mining [22].

Still, the model implementation mentioned above clearly indicates the significance and potential of using large datasets in the public administration and smart cities. The presented example from the tourism sector, however, only suggests the possibility of other useful applications in practice beyond the tourism, e.g. in gaming industry, regional development, architecture, education, health care, archaeology and others.

\section{Acknowledgements}

This research was partially supported by The Technology Agency of the Czech Republic. We thank our colleagues from The Czech Academy of Sciences, Institute of Geonics (T. Krejčí, E. Nováková, J. Malý) who provided insight and expertise that greatly assisted the research. We thank also to E. Gebauerová for assistance with particular graphics, and team of Faculty of Logistics and Crisis Management, Tomas Bata University (Department of Environmental Security, namely E. Lukášková and K. Pitrová) for comments that greatly improved the manuscript.

\section{References}

[1] Tabusca, A. (2014). Augmented Reality - Need, Opportunity or Fashion. Journal of Information Systems \& Operations Management, 1-10.

[2] Shumaker R. (2009). Virtual and Mixed Reality. Springer, 2009, Heidelberg, Deutschland. 
[3] Cragi Alan. B. (2013) Understanding Augmented Reality: Concepts and Applications. Morgan Kaufmann, 2013, Burlington, Massachusetts, USA.

[4] Gartner G., Ortag F. (2012) Advances in Location-Based Services. Springer, 2012, Heidelberg, Germany.

[5] Krisp, J. M. (2013) Progress in Location-Based Services. Springer, 2009, Heidelberg, Deutschland.

[6] Caragliu, A., Del Bo, C., \& Nijkamp, P. (2011). Smart cities in Europe. Journal of urban technology, 18(2), 65-82.

[7] Chourabi, H., Nam, T., Walker, S., Gil-Garcia, J. R., Mellouli, S., Nahon, K., Scholl, H. J. (2012). Understanding smart cities: An integrative framework. In System Science (HICSS), 2012 45th Hawaii International Conference on (pp. 2289-2297). IEEE.

[8] Schaffers, H., Komninos, N., Pallot, M., Trousse, B., Nilsson, M., Oliveira, A. (2011). Smart cities and the future internet: Towards cooperation frameworks for open innovation. In The Future Internet Assembly (pp. 431446). Springer Berlin Heidelberg.

[9] Connors J. P., Lei, S., Kelly, M. (2012). Citizen science in the age of neogeography: Utilizing volunteered geographic information for environmental monitoring. Association of American Geographers. Annals of the Association of American Geographers, 102(6), 1267.

[10] Egenhofer, M., Mark, D. (1995): Naive geography. In Frank, A. U. and Kuhn, W. (eds), Spatial Information Theory: A Theoretical Basis for GIS, Berlin: Springer Verilog, Lecture Notes in Computer Sciences No. 988, pp. 1-15.

[11] Leszczynski, A. (2014). On the neo in neogeography. Association of American Geographers. Annals of the Association of American Geographers, 104(1), 60.

[12] Liberati, N. (2016). Augmented reality and ubiquitous computing: The hidden potentialities of augmented reality. AI \& Society, 31(1), 17-28. doi:http://dx.doi.org/10.1007/s00146-014-0543-x.

[13] Dodge M., Kitchin R. (2007) Virtual places. In: Douglas, I., Huggett, R., Perkins, C. (ed.): A Companion Encyclopaedia to Geography. Routledge, London, pp. 519-536.

[14] Kitchin, R., Dodge, M. (2002) The Emerging Geographies of Cyberspace. In: Johnston, R. J. (ed.): Geographies of Global Change: Remapping the World. Blackwell Publishing, Malden, pp. 340-354.

[15] Saunders C., Rutkowski A.-F., van Genuchten M., Vogel D. R., Orrego J. M. (2011) Virtual Space and Place: Theory and Test. MIS Quarterly, 35, Nr. 4, pp. 1079-1098.

[16] Kounavis, C. D., Kasimati, A. E., Zamani, E. D. (2012). Enhancing the tourism experience through mobile augmented reality: Challenges and prospects. International Journal of Engineering Business Management, 4.

[17] Trojan J., Šinogl L. (2011) Augmented Reality and Spatiality in Tourism and Regional Development. In Georg Gartner, Felix Ortag. Proceedings of the 8th International Symposium on Location-Based Services. 1st ed. 
Vienna: Research Group Cartography, Vienna University of Technology, 2011. pp. 228-231, 333.

[18] Samardzija, A. C. (2015). Mobile augmented reality interactive systems for urban tourism. Paper presented at the 129-134.

[19] Bipin J. (2012) HTML 5 Programming for ASP.NET Developers. Apress, 2012, Berkeley, CA, USA.

[20] Dan (2013) Build a Wikitude World with Google Collaborative Maps. http://www.wikitude.com/build-wikitude-world-Google-collaborativemaps/. Accessed: 05 January 2014.

[21] Hsiao, K., Rashvand, H. F. (2015). Data modelling mobile augmented reality: Integrated mind and body rehabilitation. Multimedia Tools and Applications, 74(10), 3543-3560. doi: http://dx.doi.org/10.1007/s11042013-1649-8.

[22] Kahn, S. (2013). Reducing the gap between augmented reality and 3D modeling with real-time depth imaging. Virtual Reality, 17(2), 111-123. doi: http://dx.doi.org/10.1007/s10055-011-0203-0

[23] Lubbers P. et al. (2011) Pro HTML 5 Programming. Apress, 2011, Berkeley, CA, USA.

[24] Kourouthanassis, P. E., Boletsis, C., Lekakos, G. (2015). Demystifying the design of mobile augmented reality applications. Multimedia Tools and Applications, 74(3), 1045-1066. doi: http://dx.doi.org/10.1007/s11042-0131710-7.

[25] Madden, L. (2011) Professional Augmented Reality for Smartphones: programming for junaio, Layar and Wikitude. John Willey \& Sons, Chichester, West Sussex, UK.

[26] Apple (2016) iTunes Preview. Wikitude. Wikitude GmbH. https://itunes.Apple.com/us/app/wikitude/id329731243?mt=8. Accessed 12 August 2016.

[27] Google (2014) Google Play. Wikitude. Wikitude GmbH. https://play.Google.com/store/apps/details?id=com.wikitude. Accessed 12 August 2016.

[28] Windows (2016) Windows Phone. Wikitude. Wikitude GmbH. https:/www.microsoft.com/cs-cz/store/p/wikitude/9wzdncrfj4k4.

Accessed 12 August 2016.

[29] Apple (2016) iTunes Preview. Layar - Augmented Reality. Layar B.V. https://itunes.Apple.com/us/app/layar-augmentedreality/id334404207? $\mathrm{mt}=8$. Accessed 12 August 2016 .

[30] Google (2016) Google Play. Layar. Layar B.V. https://play.Google.com/store/apps/details?id=com.layar. Accessed 12 August 2016.

[31] Layar (2016) Layar Developer Documentation. https://www.layar.com/ documentation/. Accessed 12 August 2016.

[32] Trojan, J. (2016) Integrating AR services for the masses: geotagged POI transformation platform. Journal of Hospitality and Tourism Technology, Vol. 7 Iss: 3. 